\title{
Sequence variants in oxytocin pathway genes and preterm birth: a candidate gene association study
}

Jinsil Kim ${ }^{1}$, Kara J Stirling ${ }^{2}$, Margaret E Cooper ${ }^{3}$, Mario Ascoli ${ }^{4}$, Allison M Momany², Erin L McDonald ${ }^{2}$, Kelli K Ryckman², Lindsey Rhea ${ }^{2}$, Kendra L Schaa ${ }^{2}$, Viviana Cosentino ${ }^{5}$, Enrique Gadow ${ }^{5}$, Cesar Saleme ${ }^{6}$, Min Shi ${ }^{7}$, Mikko Hallman ${ }^{8}$, Jevon Plunkett ${ }^{9}$, Kari A Teramo ${ }^{10}$, Louis J Muglia ${ }^{11}$, Bjarke Feenstra ${ }^{12}$, Frank Geller ${ }^{12}$, Heather A Boyd ${ }^{12}$, Mads Melbye ${ }^{12}$, Mary L Marazita ${ }^{3,13}$, John M Dagle ${ }^{2}$ and Jeffrey C Murray ${ }^{1,2^{*}}$

\begin{abstract}
Background: Preterm birth (PTB) is a complex disorder associated with significant neonatal mortality and morbidity and long-term adverse health consequences. Multiple lines of evidence suggest that genetic factors play an important role in its etiology. This study was designed to identify genetic variation associated with PTB in oxytocin pathway genes whose role in parturition is well known.

Methods: To identify common genetic variants predisposing to PTB, we genotyped 16 single nucleotide polymorphisms (SNPs) in the oxytocin (OXT), oxytocin receptor (OXTR), and leucyl/cystinyl aminopeptidase (LNPEP) genes in 651 case infants from the U.S. and one or both of their parents. In addition, we examined the role of rare genetic variation in susceptibility to PTB by conducting direct sequence analysis of OXTR in 1394 cases and 1112 controls from the U.S., Argentina, Denmark, and Finland. This study was further extended to maternal triads (maternal grandparents-mother of a case infant, $N=309$ ). We also performed in vitro analysis of selected rare OXTR missense variants to evaluate their functional importance.

Results: Maternal genetic effect analysis of the SNP genotype data revealed four SNPs in LNPEP that show significant association with prematurity. In our case-control sequence analysis, we detected fourteen coding variants in exon 3 of OXTR, all but four of which were found in cases only. Of the fourteen variants, three were previously unreported novel rare variants. When the sequence data from the maternal triads were analyzed using the transmission disequilibrium test, two common missense SNPs (rs4686302 and rs237902) in OXTR showed suggestive association for three gestational age subgroups. In vitro functional assays showed a significant difference in ligand binding between wild-type and two mutant receptors.
\end{abstract}

Conclusions: Our study suggests an association between maternal common polymorphisms in LNPEP and susceptibility to PTB. Maternal OXTR missense SNPs rs4686302 and rs237902 may have gestational age-dependent effects on prematurity. Most of the OXTR rare variants identified do not appear to significantly contribute to the risk of PTB, but those shown to affect receptor function in our in vitro study warrant further investigation. Future studies with larger sample sizes are needed to confirm the findings of this study.

Keywords: Preterm birth, Genetic association analysis, Oxytocin pathway, Single nucleotide polymorphism, Rare variant

\footnotetext{
* Correspondence: jeff-murray@uiowa.edu

'Department of Anatomy and Cell Biology, University of lowa, lowa City, IA

52242, USA

2Department of Pediatrics, University of lowa, lowa City, IA 52242, USA

Full list of author information is available at the end of the article
} 


\section{Background}

Preterm birth (PTB) is a major public health problem that accounts for approximately $10 \%$ of all births worldwide [1,2]. In 2011, PTBs, occurring before 37 completed weeks of gestation, comprised $11.73 \%$ of live births in the United States [3]. Prematurity is a leading cause of perinatal mortality and in survivors is a significant contributor to short- and long-term morbidity [4]. The etiology of PTB is not completely understood, but multiple lines of evidence suggest that genetic factors play an important role in PTB, including a high rate of recurrence in individuals with a history of previous preterm delivery (PTD), a tendency to occur within families, and racial disparity [1,5-7].

The oxytocin (OXT)-oxytocin receptor (OXTR) system provides promising candidate genes for studies of genetic contributions to prematurity. Its components influence a wide range of physiological, behavioral, and emotional processes in humans, but have been most extensively studied for their role in reproduction, particularly labor and parturition [8,9]. OXT acts as an inducer of uterine contraction and the myometrium becomes increasingly sensitive to the action of OXT towards term [8]. This increase in uterine sensitivity to OXT occurs concomitantly with an upregulation of OXTR mRNA and a dramatic increase in myometrial OXTR number, which peaks during early labor [8,9]. The OXTR is a G protein-coupled receptor, which, upon stimulation, activates various intracellular signaling pathways such as the phosphoinositide cascade, eventually leading to uterine contraction $[8,10,11]$. The availability of OXT to the receptor is dependent on serum levels of leucyl/cystinyl aminopeptidase (LNPEP), an enzyme that hydrolyzes and inactivates the hormone $[12,13]$. LNPEP, also known as PLAP, increases in maternal serum during pregnancy and plays an important role in fetal development as well as pregnancy maintenance via regulating OXT levels and activity $[12,13]$. The efficacy of Atosiban, an OXT antagonist used to stop premature uterine contractions and delay PTD [14], provides further support for the importance of this hormonal system in prematurity.

Previous candidate gene association studies have provided evidence for genetic variation predisposing to PTB with four maternal and one fetal variants showing relatively consistent evidence of association [15]. In the present study, we hypothesize that allelic variations in $O X T, O X T R$, and LNPEP contribute to the genetic predisposition to prematurity. We evaluated the association between maternal and fetal genotypes of single nucleotide polymorphisms (SNPs) in the three genes and PTD in U.S. patients. We also performed direct sequence analysis in four population groups to search for rare variants in the OXT-OXTR system (particularly in the OXTR gene) that might play a role in PTB. Selected rare
OXTR variants identified in preterm cases were then further investigated to determine their functional significance.

\section{Methods \\ Study population}

The study population consisted of case and control patients from 4 countries, including the U.S. (4 sites; the University of Iowa Hospitals and Clinics in Iowa City, IA, Magee-Womens Hospital in Pittsburgh, PA, University of Rochester Medical Center in Rochester, NY, and Wake Forest University in Wake Forest, NC), Argentina (two centers; Instituto de Maternidad y Ginecología Nuestra Señora de las Mercedes in Tucumán and Hospital Provincial de Rosario in Rosario), Finland (the University of Helsinki in Helsinki), and Denmark (the island of Funen and the Danish National Birth Cohort (DNBC) [16]). All families provided signed informed consent for study enrollment in accordance with the protocols approved by research ethics committees in the U.S. (the University of Iowa Institutional Review Board (IRB), University of Pittsburgh IRB, University of Rochester Research Subjects Review Board, Wake Forest University Health Sciences IRB), Argentina (the Research Ethics Committee of Centro de Educación Médica e Investigaciones Clínicas), Finland (the Ethics Committee of the University Central Hospital, Helsinki), and Denmark (the Scientific-Ethical Committee of the Southern Danish Region and the Biomedical Research Ethics Committee of the Capital City Region of Denmark). PTD was defined as delivery before 37 completed weeks of gestation. Gestational age (GA) was determined by obstetrical assignment using the first day of the last menstrual period as well as ultrasound examination, and was confirmed by assessment at birth. Demographic and clinical data were collected by chart review and/or clinician interview. Table 1 summarizes demographic characteristics of each population studied. U.S. cases were families with either a spontaneous or medically indicated preterm birth - of note, twin births were excluded at the data analysis step. Cases from Finland (mother-infant dyads, <36 weeks' gestation) were families with spontaneous onset of preterm singleton birth from 2003 to 2009, selected using the following exclusion criteria: elective deliveries without spontaneous onset of labor and deliveries in which either maternal (e.g. systemic infection) or fetal (e.g. malformation) disease with known predisposition to premature birth was indicated. Finnish control families were defined as those with two or more children, all of whom were delivered at 37 weeks or later. The median gestational ages for index mother-infant dyads were 34 and 40 weeks for cases and controls, respectively. Danish cases and controls were identified on Funen where the University Hospital of Odense was a major participating site for case collection, and from the 
Table 1 Demographic characteristics of study populations

\begin{tabular}{|c|c|c|c|c|c|c|c|c|c|c|c|c|}
\hline & \multirow{4}{*}{$\begin{array}{c}\begin{array}{c}\text { SNP } \\
\text { genotyping }\end{array} \\
\text { U.S. } \\
N=651\end{array}$} & \multicolumn{11}{|c|}{ Resequencing } \\
\hline & & \multicolumn{9}{|c|}{ Case-control $^{3}$} & \multicolumn{2}{|c|}{ Maternal triad ${ }^{4}$} \\
\hline & & \multicolumn{3}{|c|}{ Argentina } & \multicolumn{3}{|c|}{ Denmark } & \multicolumn{3}{|c|}{ U.S. } & \multirow{2}{*}{$\begin{array}{c}\text { Argentina } \\
N=187\end{array}$} & \multirow{2}{*}{$\begin{array}{c}\text { U.S. } \\
N=109\end{array}$} \\
\hline & & Case $(N=123)$ & Control $(N=63)$ & $P$ & Case $(N=723)$ & $\begin{array}{l}\text { Control } \\
(N=920)\end{array}$ & $P$ & Case $(N=443)$ & Control $(N=34)$ & $P$ & & \\
\hline \multirow[t]{2}{*}{$\overline{\mathrm{GA}}\left(\right.$ weeks) ${ }^{1}$} & $\begin{array}{c}31.1 \pm 3.7 \\
(21-36)\end{array}$ & $\begin{array}{c}33.1 \pm 2.5 \\
(27-36)\end{array}$ & $\begin{array}{c}39.4 \pm 0.9 \\
(37-41)\end{array}$ & * & $\begin{array}{c}33.7 \pm 2.8 \\
(20-36)\end{array}$ & 40 & N/A & $\begin{array}{c}30.3 \pm 3.8 \\
(22-36)\end{array}$ & $\begin{array}{c}38.9 \pm 1.1 \\
(37-41)\end{array}$ & * & $\begin{array}{c}32.6 \pm 3.0 \\
(23-36)\end{array}$ & $\begin{array}{c}32.0 \pm 3.8 \\
(24-36)\end{array}$ \\
\hline & & & & & & & & & & & [Unknown: 5] & \\
\hline \multirow[t]{2}{*}{ Infant BW (grams) $^{1}$} & $\begin{array}{c}1739.4 \pm 814.7 \\
(332-4610)\end{array}$ & $\begin{array}{c}1834.8 \pm 514 \\
(830-3200)\end{array}$ & $\begin{array}{c}3514.1 \pm 487 \\
(2430-4950)\end{array}$ & * & $\begin{array}{l}2444 \pm 648 \\
(250-5270)\end{array}$ & $\begin{array}{r}3720.7 \pm 457 \\
(2400-5250)\end{array}$ & * & $\begin{array}{l}1606 \pm 791 \\
(332-4400)\end{array}$ & $\begin{array}{c}3495.2 \pm 417.9 \\
(2380-4275)\end{array}$ & $*$ & $\begin{array}{c}1763.3 \pm 527.2 \\
(615-3040)\end{array}$ & $\begin{array}{c}1967.5 \pm 778.2 \\
(597-3691)\end{array}$ \\
\hline & & & & & & & & & & & [Unknown: 5] & \\
\hline \multirow{2}{*}{$\begin{array}{l}\text { Infant gender } \\
{\text { (male/female })^{2}}\end{array}$} & $373 / 278$ & $65 / 57$ & $31 / 32$ & 0.64 & $385 / 338$ & $482 / 438$ & 0.77 & 249/194 & $20 / 14$ & 0.85 & $99 / 87$ & $54 / 55$ \\
\hline & & & & & & & & & & & [Unknown: 1] & \\
\hline \multirow[t]{2}{*}{$\begin{array}{l}\text { Maternal age at } \\
\text { delivery (years) }^{1}\end{array}$} & $\begin{array}{c}27.8 \pm 6.2 \\
(14-46)\end{array}$ & $\begin{array}{c}24.7 \pm 6.5 \\
(15-48)\end{array}$ & $\begin{array}{c}26.0 \pm 6.1 \\
(16-40)\end{array}$ & 0.22 & $\begin{array}{c}29.1 \pm 4.4 \\
(17-44)\end{array}$ & $\begin{array}{c}29.7 \pm 4.0 \\
(18-42)\end{array}$ & 0.001 & $\begin{array}{c}27.7 \pm 6.0 \\
(14-44)\end{array}$ & $\begin{array}{c}27.9 \pm 5.3 \\
(18-40)\end{array}$ & 0.86 & $\begin{array}{c}23.2 \pm 5.3 \\
(16-39)\end{array}$ & $\begin{array}{c}30.3 \pm 5.2 \\
(18-41)\end{array}$ \\
\hline & [Unknown: 15] & & & & & & & & & & [Unknown: 3] & [Unknown: 11] \\
\hline
\end{tabular}

${ }^{1}$ Data are presented as mean \pm standard deviation, with range in parenthesis.

${ }^{2}$ Data are presented as counts.

${ }^{3}$ Resequencing was also performed on Finnish cases $(N=105)$ and controls $(N=95)$. See the Methods section for a demographic description of this population.

${ }^{4}$ Data for Danish maternal triads $(N=13)$ are not shown.

$<0.0001$.

GA: gestational age, $B W$ : birth weight, N/A: not available. 
DNBC [16]. The DNBC consisted of 96,946 total births, including 5,352 preterm births, occurring between 1997 and 2002. We selected 723 case ( $\leq 36$ weeks gestation) and 920 control (40 weeks gestation) mothers for our study. Individuals were considered for inclusion in this study only if there was no evidence of obstetrical induction, placental abnormalities, pre-eclampsia, congenital malformations, and multiple births. Biological samples collected from mothers were stored in the Biobank at Statens Serum Institut in Copenhagen. Epidemiologic information was collected from existing medical records and from three maternal interviews, during the first trimester, at about 30 weeks gestation and 6 months after birth.

\section{SNP genotyping}

A total of 812 premature infants born in Iowa between 1999 and 2008 with GAs between 21 and 36 weeks (mean, $31 \pm 3.7$ weeks) and one or both of their parents were selected for genotyping. DNA was extracted from cord blood or discarded venous blood from the infants and venous blood, buccal swab, or saliva from the parents using standard protocols. Genotyping for SNP markers was performed using TaqMan assays (Applied Biosystems, Foster City, CA, U.S.) as described in detail elsewhere [17]. A total of 16 tagging SNPs were selected to cover haplotype blocks of the oxytocin gene (OXT; $1 \mathrm{SNP})$, the oxytocin receptor gene (OXTR; 9 SNPs), and the leucyl/ cystinyl aminopeptidase gene (LNPEP; 6 SNPs). The SNPs genotyped, along with their minor allele frequencies (MAFs), are listed in Table 2. Twin births were excluded, leaving 651 singleton infants for analysis. Of the 651 infants, 565 were successfully genotyped with GAs between 23 and 36 weeks (mean $31.1 \pm 3.75$ ).

\section{Sequencing}

A subgroup of the genotyped Iowa patients was selected for phase 1 sequencing based on GA, including 94 infants and 95 mothers of different infants with GA between 2432 weeks. All three coding exons of OXT and all four exons of $O X T R$ were sequenced in both directions, as described in prior studies [17]. Phase 2 (replication) sequencing, where we focused only on exon 3 of OXTR, was performed on cases and controls from Argentina (infants and mothers; case, $N=212$ and control, $N=125)$, Denmark (mothers participating in the DNBC; case, $N=723$ and control, $N=920$ ), Finland (mothers; case, $N=105$ and control, $N=95$ ), and the U.S. (infants and mothers; case, $N=719$ and control, $N=229$ ). Removal of twin births as well as unsuccessfully genotyped individuals left a very small number of Argentinian and U.S. controls, making a case-control association analysis particularly for the Argentinian population impossible.

To assess the effect of maternal OXTR genotype on the risk of PTD, we performed sequence analysis on the
Table 2 List of SNPs in the OXT, OXTR, and LNPEP genes genotyped

\begin{tabular}{|c|c|c|c|c|c|}
\hline Gene & SNP & Alleles & Chr & Position $^{1}$ & MAF \\
\hline OXT & rs2740210 & $\mathrm{G} / \mathrm{T}$ & 20 & 3053255 & 0.32 \\
\hline \multirow[t]{9}{*}{ OXTR } & rs7632287 & $A / G$ & 3 & 8791446 & 0.25 \\
\hline & rs11706648 & $\mathrm{A} / \mathrm{C}$ & 3 & 8796547 & 0.33 \\
\hline & rs237887 & $A / G$ & 3 & 8797042 & 0.41 \\
\hline & rs4686301 & $\mathrm{C} / \mathrm{T}$ & 3 & 8798586 & 0.29 \\
\hline & rs237889 & $\mathrm{C} / \mathrm{T}$ & 3 & 8802483 & 0.37 \\
\hline & rs53576 & $\mathrm{A} / \mathrm{G}$ & 3 & 8804371 & 0.32 \\
\hline & rs237893 & $A / G$ & 3 & 8805950 & 0.42 \\
\hline & rs237897 & $A / G$ & 3 & 8808285 & 0.36 \\
\hline & rs4686302 & $\mathrm{C} / \mathrm{T}$ & 3 & 8809222 & 0.12 \\
\hline \multirow[t]{6}{*}{ LNPEP } & rs4869315 & $\mathrm{A} / \mathrm{G}$ & 5 & 96229272 & 0.44 \\
\hline & rs3849749 & $\mathrm{A} / \mathrm{T}$ & 5 & 96234533 & 0.41 \\
\hline & rs4869317 & $\mathrm{A} / \mathrm{T}$ & 5 & 96292004 & 0.28 \\
\hline & rs18059 & $\mathrm{C} / \mathrm{T}$ & 5 & 96352068 & 0.48 \\
\hline & rs316206 & $\mathrm{C} / \mathrm{T}$ & 5 & 96380733 & 0.32 \\
\hline & rs13175726 & $\mathrm{A} / \mathrm{G}$ & 5 & 96387033 & 0.29 \\
\hline
\end{tabular}

${ }^{1}$ Position according to NCBI Build 37.3 GRCh37.p5 assembly.

SNP: single nucleotide polymorphism, Chr: chromosome, MAF: minor allele frequency.

same region of $O X T R$ in maternal triads (each including a mother of a premature infant with GA between 23 and 36 weeks (single gestation, born after spontaneous onset of labor) and her parents) as well as in a small group of patients consisting of 71 case and 64 control mothers. These case and control mothers were all Caucasians from Iowa with a singleton spontaneous delivery between 2005 and 2010. Further exclusion criteria for cases include preeclampsia and induction of labor. Of the 71 cases (mothers of preterm infants with GA between 2328 weeks and birth weight (BW) between 413 and 1770 grams) and the 64 controls (mothers of term infants with GA between 39-42 weeks and BW between 2050 and 4756 grams), 62 cases and 60 controls with complete data were included in the analysis. The maternal grandmother-grandfather-mother triads were created from 309 pedigrees from different populations, including Argentina ( 2 centers, $N=187$ ), Denmark (the island of Funen, $N=13$ ), and the U.S. (4 sites, $N=109$ ). The families were enrolled in the study between 2005 and 2010 (Argentina and U.S.) and between 2008 and 2009 (Denmark). Of note, the small sample size of the Danish group $(N=13)$ made statistical analysis uninformative. DNA was extracted from venous blood or saliva (Argentina), saliva (Denmark), and venous blood, buccal swab, or saliva (U.S.) and subsequently used for sequencing. All sequencing was performed by Functional Biosciences, Inc., Madison, WI, U.S. 


\section{Plasmids and cells}

A full-length cDNA encoding human OXTR [GenBank: AY389507] was obtained from the Missouri S\&T cDNA Resource Center (Rolla, MO, U.S.). Site-directed mutagenesis was performed to generate mutant constructs possessing missense mutations of potential functional significance identified in premature cases, including P108A, W203R, and F284. The mutations were introduced individually into the wild-type OXTR sequence using a PCR-based mutagenesis strategy. The wild-type and mutant full-length cDNAs were inserted into the EcoRI and XhoI sites of expression vector pcDNA3.1 (+) (Invitrogen, Carlsbad, CA, U.S.). The sequence of all constructs was confirmed by sequencing.

African green monkey kidney COS-7 cells were maintained in Dulbecco's Modified Eagle's Medium supplemented with $10 \%$ newborn calf serum, $50 \mu \mathrm{g} / \mathrm{mL}$ gentamicin, and $10 \mathrm{mM}$ HEPES, $\mathrm{pH}$ 7.4. Cells were plated at a density of $4 \times 10^{5}$ cells/well in 6-well $(35-\mathrm{mm})$ plates, and transiently transfected with plasmid DNA using FuGENE ${ }^{\oplus}$ HD Transfection Reagent (Roche Applied Science, Indianapolis, IN, U.S.) according to the manufacturer's instructions. After overnight incubation, the cells were washed and used in subsequent experiments.

\section{Inositol phosphate assays}

The accumulation of inositol phosphates was measured using $\left[{ }^{3} \mathrm{H}\right]$ inositol-labeled cells incubated in the absence or presence of $100 \mathrm{nM}$ oxytocin for $1 \mathrm{~h}$ as described elsewhere [18]. Results were presented as mean fold difference between stimulated and unstimulated values (in $\mathrm{cpm} / 10^{6}$ cells) or mean ratio of the basal level in each transfection group to that in the wild-type group.

\section{Ligand binding assays}

Two days after transfection, cells were washed twice with warm buffer (20 mM HEPES, $0.15 \mathrm{M} \mathrm{NaCl}, 1 \mathrm{mg} /$ $\mathrm{ml}$ bovine serum albumin, $\mathrm{pH} 7.4$ ), and incubated with 50 nM $\left[{ }^{3} \mathrm{H}\right]$ oxytocin (PerkinElmer, Waltham, MA, U.S.) alone (total binding) or together with $20 \mu \mathrm{M}$ unlabeled oxytocin (nonspecific binding). After 2.5 hours of incubation at room temperature, the cells were washed twice with cold buffer and dissolved in $0.5 \mathrm{ml}$ of $0.5 \mathrm{~N} \mathrm{NaOH}$ overnight. After collecting the lysate, each well was washed with another $0.5 \mathrm{ml}$ of $0.5 \mathrm{~N} \mathrm{NaOH}$, and the wash was combined with the lysate, followed by neutralization with $0.25 \mathrm{ml}$ of $2 \mathrm{~N} \mathrm{HCl}$ prior to measuring radioactivity. Specific binding was determined by calculating the difference between total and nonspecific binding and was expressed as mean cpm $/ 10^{6}$ cells.

\section{Statistical analysis}

The common SNP genotyping data were tested for genotype deviation from the Hardy-Weinberg equilibrium
(HWE) using PLINK [19] and Haploview [20]. We first analyzed the data for all GAs together and then performed stratified analyses. For both maternal and fetal effects, five-week sliding windows of GA were utilized, starting with 21-25 weeks and ending with 32-36 weeks. For fetal effect analysis, three-stage stratification was additionally used, resulting in three GA groups: early (between 21 and 27 weeks), middle (between 28 and 30 weeks), and late (between 31 and 36 weeks). We performed a transmission disequilibrium test (TDT) using the Family Based Association Test (FBAT) software $[21,22]$, which analyzes overtransmission of alleles to an affected fetus [23]. For maternal genetic effect analysis, we used a log-linear approach to study maternallymediated effects [24]. This approach uses a case-parents triad as the analysis unit and it tests maternally-mediated genetic effects based on the symmetry assumption of allele counts between the mothers and the fathers in the source population [25]. We performed likelihood ratio tests of the maternal genetic effects. The expectationmaximization algorithm was applied to fully utilize families with missing parental genotypes [26]. We also performed a haplotype analysis for all the six SNPs in the LNPEP gene using TRIMM [27]. The test statistics was constructed based on the vector of genotype differences between the mother and the father. Under genetic mating symmetry assumption, the difference vector has an expected value of 0 at each locus under the null hypothesis. A permutation test was used to evaluate the significance of the test statistic.

The sequencing data from the maternal triads were analyzed in a similar way except that we defined as affected those (mothers) who delivered preterm infants and used GA and BW of the infants as phenotypes of the case mothers. We performed a TDT using the FBAT program [21,22] for each common or rare variant found in the sequenced region. The data were analyzed for all GAs together as well as for GA subgroups using fiveweek sliding windows of GA and three-stage (early, middle, and late) stratification as described above.

We performed chi-square and Fisher's exact tests using SAS version 9.2 statistical program (SAS, Cary, NC, U.S.) for a 2 by 2 or 2 by 3 contingency table to analyze the sequence data on rare and common OXTR variants found in cases and controls from Argentina, Denmark, Finland, and the U.S. as well as a small group of Caucasian case and control mothers from Iowa. In the Iowa case and control study, we restricted our analysis to only 3 common polymorphisms (rs4686302, rs237902, and rs61740241) because of the absence of rare variant minor alleles in both cases and controls.

The Danish sequencing data were further analyzed using linear regression to model genetic effects of the OXTR variants identified on GA. In the Iowa case- 
control study, we conducted logistic regression analysis to predict case/control status and linear regression analyses to predict GA (weeks) and BW (grams) on the aforementioned three OXTR polymorphisms.

Data for inositol phosphate and ligand binding assays were analyzed using one-way ANOVA, followed by Dunnett's test with InStat software (GraphPad, La Jolla, CA, U.S.).

\section{Analysis of genetic variation in OXTR using publicly available reference data}

The OXTR sequencing results from our study were additionally analyzed utilizing publicly available data from two databases: 1) the 1000 Genomes Project (1000GP) $[28,29]$, which provides a catalogue of genetic variants present in the genomes of healthy individuals from different ethnic groups, and 2) the National Heart, Lung, and Blood Institute (NHLBI) Grand Opportunity (GO) Exome Sequencing Project (ESP) [30], which provides a catalogue of exome variants present in the genomes of approximately 2500 European and African American individuals from cohorts sampled for heart, lung, and blood diseases . No data on these for GA is reported. We investigated the two databases in search of coding variants in exon 3 of the OXTR gene in European Americans and African Americans, and then compared the variants retrieved with those identified in our sequencing study. The variants reported in the 1000GP (February 2012 release, 20120316) [28,29] were annotated using the SeattleSeq Annotation Server [31].

\section{Results}

Effects of common polymorphisms in the OXT pathway genes on risk of PTB

We selected 16 SNPs in the OXT, OXTR, and LNPEP genes based on haplotype block structures and examined them for their association with PTB in patients from the U.S. (Iowa). All SNPs tested had a MAF greater than 10\% (Table 2). Excluding one SNP (rs237889) with HWE violation $\left(p=8 \times 10^{-5}\right)$ and one SNP (rs4686302) with insufficient informative families $(n<10)$ left a total of 14 SNPs for analysis.

\section{Fetal genetic effects}

Figure 1 shows the $p$-values obtained from fetal effect analysis, using the entire set of data as well as subsets classified by GA. There was no significant SNP found either when all GAs were examined together (Figure 1A) or when the GA-stratified analyses were performed (Figure $1 \mathrm{~A}$ and $1 \mathrm{~B}$ ).

\section{Maternal genetic effects}

Figure 2 summarizes the results from the analysis of maternally mediated genetic effects. When the analysis was performed on all GA cases (Figure 2A), three SNPs in $L N P E P$ were found to have a $p$-value of less than 0.05 (rs4869315, $p=0.035 ;$ rs3849749, $p=0.019$; rs4869317, $p=0.006)$. These values are uncorrected for the multiple comparisons done in this study where a Bonferroni corrected $p$-value for significance would be $<0.002$ accounting for 14 SNPs and both maternal and fetal comparisons. When the analysis was stratified by GA using five-week sliding windows (Figure 2B), the same variants in LNPEP remained significant - rs4869315 for the $30-34(p=0.019)$ and 32-36 $(p=0.009)$ week GA groups, rs3849749 for the 32-36 ( $p=0.016)$ week GA group, and rs4869317 for the $31-35(p=0.024)$ and 32-36 $(p=0.012)$ week GA groups. Another LNPEP SNP, rs13175726 $(p=0.035)$ was additionally found to be significant for the 26-30 week GA group. Haplotype analysis of all 6 SNPs in $L N P E P$ failed to yield any significant results.
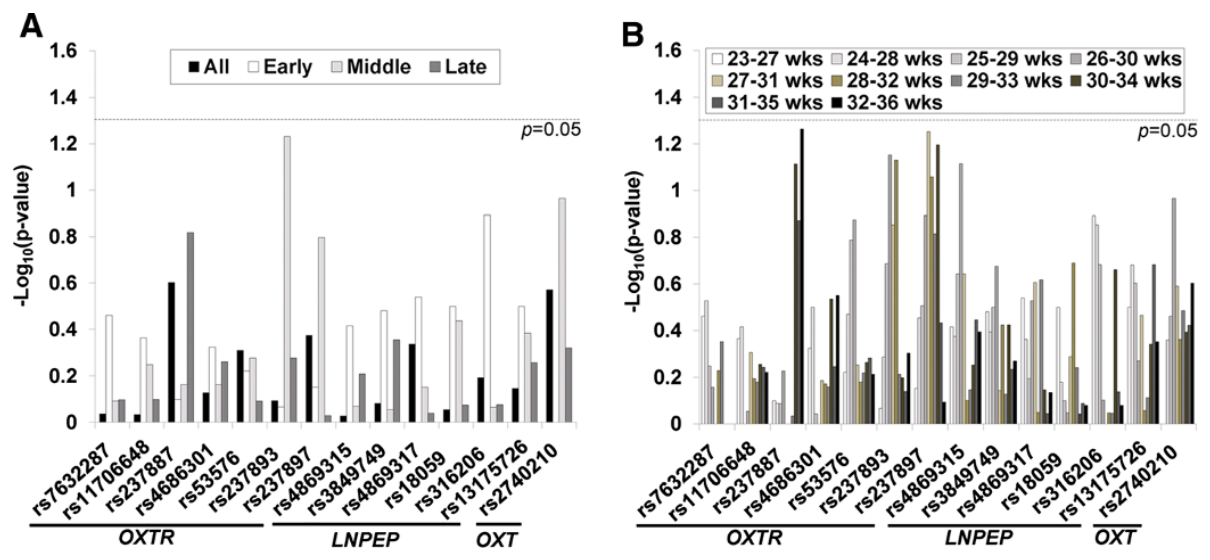

Figure 1 Results of fetal genetic effect analysis. No statistically significant $(p<0.05)$ association was found between any of the SNPS in the OXT, OXTR, and LNPEP genes and preterm birth risk either when all GAs together were evaluated (A) or when three-stage (A) or five-week sliding window (B) stratification was used. 

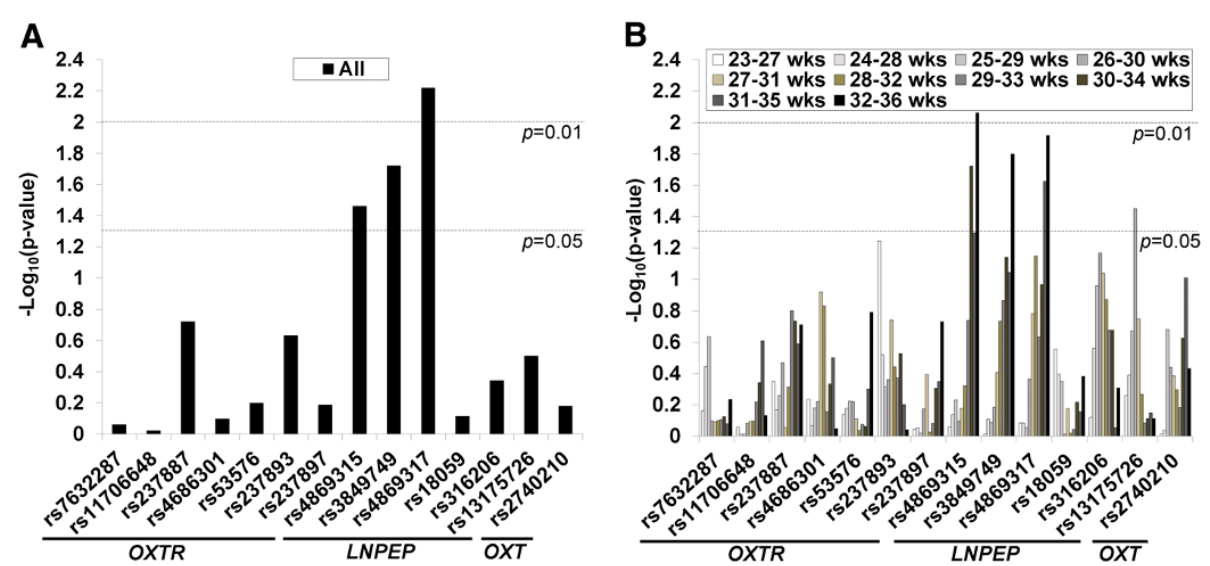

Figure 2 Results of maternal genetic effect analysis. Three SNPS (rs4869315, rs3849749, rs4869317) in the LNPEP gene were significantly associated with preterm birth when all GAs were together considered (A). Another SNP (rs13175726) in LNPEP as well as the same three SNPS were found to be significant for several GA subgroups (B)

\section{Analysis of rare variants in the OXTR gene for the association with PTB \\ Rare sequence variations in OXTR: phase 1 and phase 2 case-control resequencing studies}

Lack of association between common polymorphisms in $O X T$ and $O X T R$ led us to examine whether there exist (s) rare genetic variant(s) in these two genes with potential effects on the risk of prematurity. To this end, we first sequenced all exons of $O X T$ and $O X T R$ in a subgroup $(n=189)$ of the genotyped (U.S.) patients. This pilot (hereinafter referred to as "phase 1") sequencing analysis revealed only previously reported SNPs in the $O X T$ gene. In $O X T R$, we found three rare variants (V172A, L206V, W203R, Table 3) that were not present in public databases at the time of the data analysis. Of note, the mutant allele at codon 206 was always detected together with that at codon 172, indicative of a rare double-mutant haplotype, while the V172A rare allele was identified both on its own and together with the L206V rare allele. We found that all the missense variants identified were located in one high-yield amplicon of $O X T R$, which corresponds to exon 3, and therefore attempted to replicate these phase 1 sequencing results in more individuals.

Phase 2 (replication) sequencing was performed on preterm cases and term controls from the U.S., Argentina, Finland, and Denmark (Table 1). The OXTR variants identified and their locations in the receptor are shown in Table 3 and Figure 3, respectively. The F284L mutation (rs201783860), which was detected in one case mother from the U.S., was also transmitted to the infant. In a well-characterized cohort of case ( $\leq 36$ weeks gestation, $N=723$ ) and control (40 weeks gestation, $N=920$ ) mothers selected from the DNBC Study [16], we found three novel variants, including A11T, V211L, and A247A (Table 3). All but four (V45L, V211L, A247A, and G252A) rare coding variants identified in phase 1 and 2 studies were found in cases only.

To gain a more complete understanding of the spectrum of genetic variation in exon 3 of OXTR and the importance of the identified $O X T R$ rare variants in predisposition to PTB, we examined recent data from the 1000 Genomes Project (1000GP) [28,29] and the NHLBI GO Exome Sequencing Project (NHLBI_ESP) [30] (see Methods for more details). A list of coding variants in exon 3 of OXTR reported in the two databases is shown in Additional file 1. We compared this list with our sequencing results and found 5 variants (V45L, V172A, L206V, G252A, and V281M) overlapping with our data in individuals of European origin. It was particularly noted that two (V172A and L206V) of the 5 variants occur at much higher frequencies in African Americans (MAF: V172A, 5.52\% and L206V, 1.84\%) than in European Americans (MAF: V172A, 0.01\% and L206V, 0.01\%). It would be interesting to explore if these variants play a role in prematurity, given that about $10 \%$ of normal individuals whose sequences are catalogued in the databases are expected to be preterm and that PTB rates are higher in African Americans than in whites [32]. In addition, we found 4 rare variants (A11T, P108A, W203R, and F284L) that are present exclusively in our cases with PTB. Importantly, three of them were predicted to have functional effects by PolyPhen [33] and SIFT [34] (Table 4), suggesting that they are potentially etiologic.

Association analysis of all rare coding variants identified by phase 1 and 2 sequencing showed no significant results - either when the variants were tested individually or when all missense variants were combined and analyzed together (Table 5).

We further extended our analysis on Danish mothers, in particular, and performed regression analyses to more precisely define the effects of OXTR genetic variation on 
Table 3 Summary of all OXTR coding variants detected by resequencing in the present study

\begin{tabular}{|c|c|c|c|c|c|c|c|c|c|}
\hline \multirow[t]{3}{*}{ Position $^{1}$} & \multirow{3}{*}{$\begin{array}{l}\text { Nucleotide } \\
\text { variation }^{2}\end{array}$} & \multirow{3}{*}{$\begin{array}{l}\text { Amino acid } \\
\text { substitution }\end{array}$} & \multirow{3}{*}{$\begin{array}{l}\text { Domain } \\
\text { location }\end{array}$} & \multirow[t]{3}{*}{ dbSNP ID } & \multirow[t]{3}{*}{ Sequencing analysis ${ }^{3}$} & \multicolumn{4}{|c|}{ Number of variant carriers ${ }^{4}$} \\
\hline & & & & & & \multicolumn{2}{|c|}{ Mother } & \multicolumn{2}{|c|}{ Infant } \\
\hline & & & & & & Case & Control & Case & Control \\
\hline 8809843 & $+31 \mathrm{C}>\mathrm{T}$ & $\mathrm{A} 11 \mathrm{~T}$ & END & & Case-control (P2) & $1(\mathrm{D})$ & 0 & 0 & 0 \\
\hline 8809741 & $+133 \mathrm{C}>\mathrm{A}$ & V45L & TMD 1 & & Case-control (P2) & 0 & $2(D)$ & 0 & 0 \\
\hline 8809552 & $+322 \mathrm{G}>\mathrm{C}$ & P108A & ECL 1 & rs202138705 & Case-control (P2), MT & $1(\mathrm{~F})$ & 0 & 0 & 0 \\
\hline 8809446 & $+428 \mathrm{~T}>\mathrm{C}$ & Q143R & $\mathrm{ICL} 2$ & & MT & & & & \\
\hline 8809359 & $+515 \mathrm{~A}>\mathrm{G}$ & V172A & TMD 4 & rs115324487 & Case-control (P1 and P2), MT & $7(A, U)$ & 0 & $5(A, U)$ & 0 \\
\hline 8809267 & $+607 A>G$ & W203R & $\mathrm{ECL} 2$ & rs200498154 & Case-control (P1) & 0 & 0 & $1(U)$ & 0 \\
\hline 8809258 & $+616 \mathrm{G}>\mathrm{C}$ & $L_{2} 206 V^{5}$ & TMD 5 & rs150746704 & Case-control (P1 and P2) & $2(U)$ & 0 & $3(A, U)$ & 0 \\
\hline 8809243 & $+631 \mathrm{C}>\mathrm{A}$ & V211L & TMD 5 & & Case-control (P2) & 1 (D) & 1 (D) & 0 & 0 \\
\hline 8809222 & $+652 C>T$ & A218T & TMD 5 & rs4686302 & All & & & & \\
\hline 8809184 & $+690 \mathrm{G}>\mathrm{A}$ & $\mathrm{N} 230 \mathrm{~N}$ & ICL 3 & rs237902 & All & & & & \\
\hline 8809162 & $+712 C>T$ & A238T & ICL 3 & rs61740241 & All & & & & \\
\hline 8809150 & $+724 C>G$ & E242Q & ICL 3 & & MT & & & & \\
\hline 8809133 & $+741 C>T$ & A247A & ICL 3 & & Case-control (P2) & $2(D)$ & $1(\mathrm{D})$ & 0 & 0 \\
\hline 8809119 & $+755 C>G$ & G252A & $\mathrm{ICL} 3$ & rs151141371 & Case-control (P2), MT & $3(D)$ & $2(D, F)$ & 0 & 0 \\
\hline 8809033 & $+841 \mathrm{C}>\mathrm{T}$ & V281M & TMD 6 & rs144814761 & Case-control (P2) & $1(\mathrm{D})$ & 0 & 0 & 0 \\
\hline 8809024 & $+850 A>G$ & $F 284 L^{6}$ & TMD 6 & rs201783860 & Case-control (P2) & $1(U)$ & 0 & 0 & 0 \\
\hline
\end{tabular}

${ }^{1}$ Position (on chromosome 3) according to NCBI Build 37.3 GRCh37.p5 assembly.

${ }^{2}$ Nucleotide numbering: +1 is the $A$ of the ATG translation initiation codon.

${ }^{3}$ Sequencing analysis in which the variant indicated was detected. See text for further details.

${ }^{4}$ Counts of common variant (A218T, N230N, and A238T) carriers are not shown. Counts from maternal triad analysis were not included: P108A, Q143R, V172A,

E242Q, and G252A were identified each in one family. Letter in parentheses is a population code: A: Argentina, D: Denmark, F: Finland, and U: U.S.

${ }^{5}$ Always found together with V172A.

${ }^{6}$ Identified in a twin case and not considered for formal association analysis.

ECL: extracellular loop, END: extracellular N-terminal domain, ICL: intracellular loop, TMD: transmembrane domain, P1: phase 1, P2: phase 2, MT: maternal triad.

GA. We modeled the effects of all coding variants (both common and rare) identified by sequencing on GA treated as either a continuous (in weeks) or categorical (preterm, $\leq 36$ weeks; and term, 40 weeks) variable. However, no results were found to be significant in both analyses (Additional file 2).

Maternal OXTR sequence variation and susceptibility to PTB To address in more depth the importance of maternal genetic effects on the risk of PTB, we extended the results obtained from the study of Danish mothers by performing sequence analysis of $O X T R$ in maternal triads

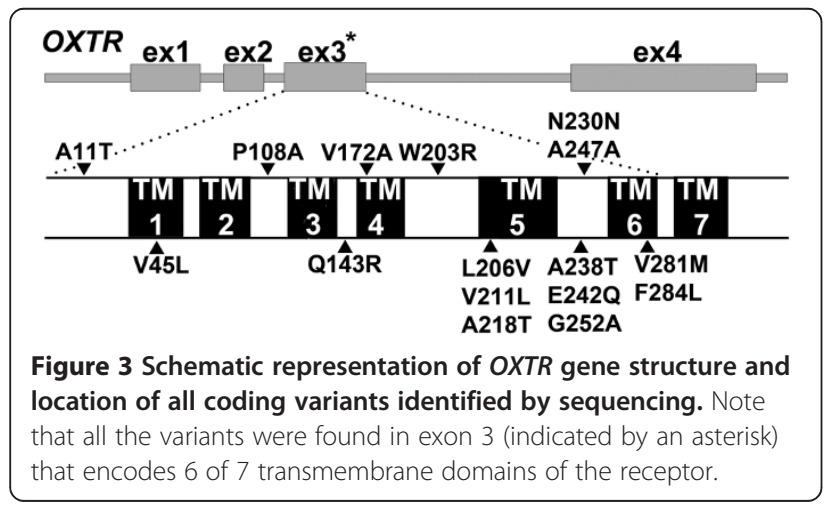

created from 309 pedigrees from the U.S., Argentina, and Denmark (Table 1) as well as in a small group of Caucasian patients from Iowa consisting of case $(n=71)$ and control $(n=64)$ mothers. Each maternal triad consisted of a mother of a preterm infant with GA between 23 and 36 weeks and her parents (grandmother-grandfathermother), and we examined the transmission of OXTR variant alleles from maternal grandparents to the mothers of affected infants using the transmission disequilibrium test (TDT).

Among 8 coding variants identified by sequencing, two (Q143R and E242Q) were previously unreported novel variants (Table 3). Our TDT analysis did not reveal any significant association either when we examined all GAs together (Figure 4) or three subgroups (early, middle, and late) stratified by GA. (Of note, due to very low frequencies of rare variant minor alleles, complete results were available only for 3 SNPs (rs4686302, rs237902, and rs61740241) with more than 10 informative families.) However, when we performed a stratified analysis for the U.S. triads $(N=109)$ using five-week sliding windows of GA, rs4686302 and rs237902 were found to be significant for the 24-28 and 28-32 week groups and the 27-31 and 28-32 week groups, respectively (Figure 4 ). 
Table 4 In silico prediction of functional significance of OXTR missense variants identified by resequencing

\begin{tabular}{|c|c|c|c|c|}
\hline \multirow{2}{*}{$\begin{array}{l}\text { Amino acid } \\
\text { change }\end{array}$} & \multicolumn{2}{|c|}{ PolyPhen } & \multicolumn{2}{|c|}{ SIFT } \\
\hline & Prediction & PSIC score difference & Prediction & Tolerance index \\
\hline A11T & Benign & N/A & Tolerated & 0.44 \\
\hline V45L & Benign & $\mathrm{N} / \mathrm{A}$ & Tolerated & 0.11 \\
\hline P108A* & Probably damaging & 2.243 & Affect protein function & 0.04 \\
\hline Q143R & Benign & 0.286 & Tolerated & 0.67 \\
\hline V172A & Benign & 0.820 & Tolerated & 0.37 \\
\hline W203R & Probably damaging & 4.115 & Affect protein function & 0.00 \\
\hline L206V & Benign & 0.319 & Tolerated & 0.41 \\
\hline V211L & Benign & $\mathrm{N} / \mathrm{A}$ & Tolerated & 0.41 \\
\hline A218T & Benign & 0.324 & Tolerated & 0.36 \\
\hline $\mathrm{A} 238 \mathrm{~T}$ & Benign & 0.330 & Tolerated & 0.59 \\
\hline E242Q & Benign & 0.740 & Tolerated & 0.59 \\
\hline G252A & Benign & 0.278 & Tolerated & 0.74 \\
\hline $\mathrm{V} 281 \mathrm{M}^{*}$ & Probably damaging & 2.013 & Affect protein function & 0.00 \\
\hline F284L $^{*}$ & Probably damaging & 2.208 & Affect protein function & 0.01 \\
\hline
\end{tabular}

"Amino acid substitutions with predicted deleterious effects.

The three SNPs were further studied in the Iowa casecontrol study (71 case and 64 control mothers). We first developed logistic regression models to predict case/control status, and found that the model containing the two polymorphisms rs4686302 and rs237902 best explains case-control status ( $p=0.04,0.05$, respectively, $\mathrm{R}^{2}=0.062$ ) (Table 6). Next, linear regression analyses were performed to predict GA and BW. As demonstrated in Table 6, the models containing (rs237902 + rs61740241) and (rs4686302 + rs61740241) were best at predicting lower GA $\left(p=0.03,0.04, \mathrm{R}^{2}=0.055\right)$ and lower $\mathrm{BW}(p=0.008$, $\left.0.01, R^{2}=0.074\right)$, respectively. The results indicate that 2 SNPs significantly explain $5.5 \%$ of the variation in GA and $7.3 \%$ of the variation in BW with rs61740241 in a slightly more supportive role to the other SNP. The SNPs that best predict case-control status are identical to the SNPs involved as the main predictors of GA in weeks and BW in grams.

Table 5 Association of OXTR rare coding variants with preterm birth in Danish, Finnish, and U.S. populations

\begin{tabular}{|c|c|c|c|c|c|c|c|}
\hline \multirow[t]{4}{*}{ Position $^{1}$} & \multirow{4}{*}{$\begin{array}{l}\text { Rare } \\
\text { allele }\end{array}$} & \multirow{4}{*}{$\begin{array}{l}\text { Amino acid } \\
\text { substitution }\end{array}$} & \multirow[t]{4}{*}{ dbSNP ID } & \multicolumn{4}{|c|}{ Population } \\
\hline & & & & \multirow{3}{*}{$\begin{array}{c}\text { Denmark }^{2} \\
N=723 \text { (case) } / 920 \text { (control) } \\
\text { Mother }\end{array}$} & \multirow{3}{*}{$\begin{array}{c}\text { Finland }^{2} \\
N=105 \text { (case) } / 95 \text { (control) } \\
\text { Mother }\end{array}$} & \multirow{2}{*}{\multicolumn{2}{|c|}{$\begin{array}{c}\text { U.S. }^{3} \\
N=443 \text { (case) / } 34 \text { (control }\end{array}$}} \\
\hline & & & & & & & \\
\hline & & & & & & Mother & Infant \\
\hline 8809843 & $\mathrm{~T}$ & $\mathrm{~A} 11 \mathrm{~T}$ & & 0.43 & - & - & - \\
\hline 8809741 & A & V45L & & 0.51 & - & - & - \\
\hline 8809552 & $C$ & P108A & rs202138705 & - & 1.00 & - & - \\
\hline 8809359 & G & V172A & rs115324487 & - & - & 1.00 & 1.00 \\
\hline 8809267 & G & W203R & rs200498154 & - & - & N/A & N/A \\
\hline 8809258 & $C$ & L206V & rs150746704 & - & - & 1.00 & 1.00 \\
\hline 8809243 & A & V211L & & 1.00 & - & - & - \\
\hline 8809133 & $\mathrm{~T}$ & A247A & & 1.00 & - & - & - \\
\hline 8809119 & G & G252A & rs151141371 & 0.33 & 0.43 & - & - \\
\hline 8809033 & $\mathrm{~T}$ & V281M & rs144814761 & 0.44 & - & - & - \\
\hline \multicolumn{4}{|c|}{ All missense variants combined ${ }^{4}$} & 0.35 & 1.00 & 1.00 & 1.00 \\
\hline
\end{tabular}

${ }^{1}$ Position (on chromosome 3) according to NCBI Build 37.3 GRCh37.p5 assembly.

${ }^{2}$ Subjects include mothers only.

${ }^{3}$ Subjects include both mothers and infants.

${ }^{4}$ All missense variants detected in each population were combined together for analysis.

- Variant not found in the population indicated. 


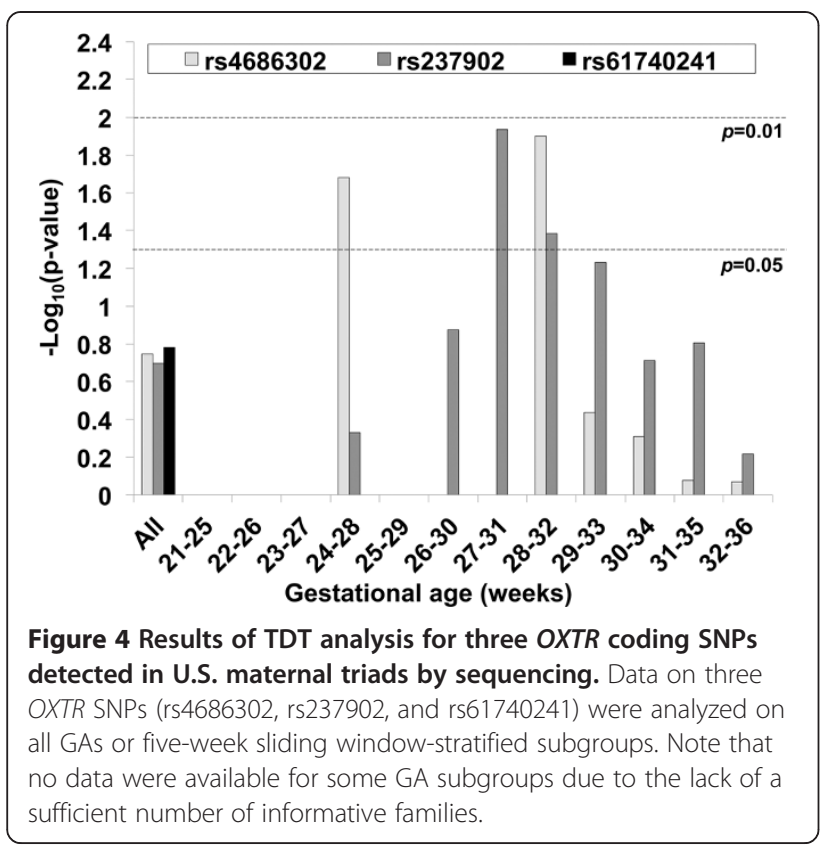

Functional analysis of OXTR missense mutations and polymorphisms

We performed in vitro functional studies on the aforementioned three OXTR missense mutations (P108A, W203R, and F284L) that were uniquely identified in our PTB cases and predicted as deleterious by PolyPhen [33] and SIFT [34] (Table 4). We first tested the ligandbinding properties of the mutant receptors, using transiently transfected COS-7 cells. To this end, the level of $\left[{ }^{3} \mathrm{H}\right] \mathrm{OXT}$ binding was assessed in empty vector-, wildtype or mutant OXTR-expressing cells in the presence or absence of excess unlabeled OXT. The specific binding of $\left[{ }^{3} \mathrm{H}\right] \mathrm{OXT}$ to intact transfected cells was defined as the difference between total and non-specific binding. We initially observed a considerable decrease in specific binding in cells transfected with the mutant plasmids, compared to those transfected with the wild-type plasmid. Because this could be a reflection of lower expression of the mutant receptor proteins, we attempted to increase their expression levels using twice more plasmid DNA (4 $\mu$ g per well). However, the mean binding levels (in cpm/million cells) in each transfection group hardly varied. Based on this observation, we combined data from all experiments performed, regardless of the amount of transfected DNA. As shown in Figure 5, two of the three mutations (P108A and W203R) tested exhibited a statistically significant reduction in $\left[{ }^{3} \mathrm{H}\right] \mathrm{OXT}$ binding. For the W203R mutation, there was nearly complete abolishment of specific binding. Our results suggest that these mutations may cause either reduced receptor expression or ligand affinity, leading to impaired ligand binding.

To gain insight into whether the missense mutations affect receptor signaling, OXT-stimulated inositol phosphate (InsP) production by wild-type and mutant OXTRs was evaluated. Figure 6A summarizes the results obtained. The accumulation of $\left[{ }^{3} \mathrm{H}\right]$ InsPs increased more than twofold in response to oxytocin in wild-type OXTRexpressing cells, while this increase was not observed in mutant plasmid- and empty vector-transfected cells. In addition, basal (unstimulated) levels of inositol phosphates were almost indistinguishable between wild-type OXTR and the three mutant receptors (Figure 6B), suggesting that the mutant receptors are unlikely to be constitutively active. Taken together, these data indicate that the examined mutations may have no effect on the coupling of the receptor to the second messenger signaling system.

Table 6 Results of regression analyses of OXTR coding variants detected in lowa case and control mothers

\begin{tabular}{|c|c|c|c|c|c|}
\hline (A) Model ${ }^{1}$ & $n$ (case, control) & \multicolumn{2}{|c|}{$P$} & \multicolumn{2}{|c|}{ R2 } \\
\hline rs4686302 (A218T) & 60,60 & \multicolumn{2}{|c|}{0.19} & \multicolumn{2}{|c|}{0.020} \\
\hline rs237902 (N230N) & 60,60 & \multicolumn{2}{|c|}{0.24} & \multicolumn{2}{|c|}{0.015} \\
\hline rs61740241 (A238T) & 60,59 & \multicolumn{2}{|c|}{0.75} & \multicolumn{2}{|c|}{0.001} \\
\hline rs4686302 (A218T) + rs237902 (N230N) ${ }^{2}$ & 60,60 & \multicolumn{2}{|c|}{$0.04,0.05^{3}$} & \multicolumn{2}{|c|}{0.062} \\
\hline \multirow[t]{2}{*}{ (B) Model ${ }^{1}$} & \multirow[t]{2}{*}{$n$} & \multicolumn{2}{|c|}{ Gestational age } & \multicolumn{2}{|c|}{ Birth weight } \\
\hline & & $P$ & R2 & $P$ & R2 \\
\hline rs4686302 (A218T) & 120 & 0.14 & 0.019 & 0.08 & 0.025 \\
\hline rs237902 (N230N) & 120 & 0.23 & 0.022 & 0.17 & 0.016 \\
\hline rs61740241 (A238T) & 119 & 0.77 & 0.001 & 0.53 & 0.003 \\
\hline rs237902 (N230N) + rs61740241 (A238T) & 120 & $0.03,0.04$ & 0.055 & N/A & $\mathrm{N} / \mathrm{A}$ \\
\hline rs4686302 (A218T) + rs61740241 (A238T) $)^{5}$ & 120 & $\mathrm{~N} / \mathrm{A}$ & $\mathrm{N} / \mathrm{A}$ & $0.008,0.01$ & 0.074 \\
\hline
\end{tabular}

${ }^{1}$ (A) Logistic regression analysis to predict case/control status and (B) Linear regression analysis to predict gestational age and birth weight.

${ }^{2}$ The most parsimonious model for predicting case/control status.

${ }^{3}$ rs4686302 OR=2.861 (1.041, 7.859) and rs237902 OR=1.803 (0.993, 3.273).

${ }^{4}$ The most parsimonious model for predicting gestational age.

${ }^{5}$ The most parsimonious model for predicting birth weight. 


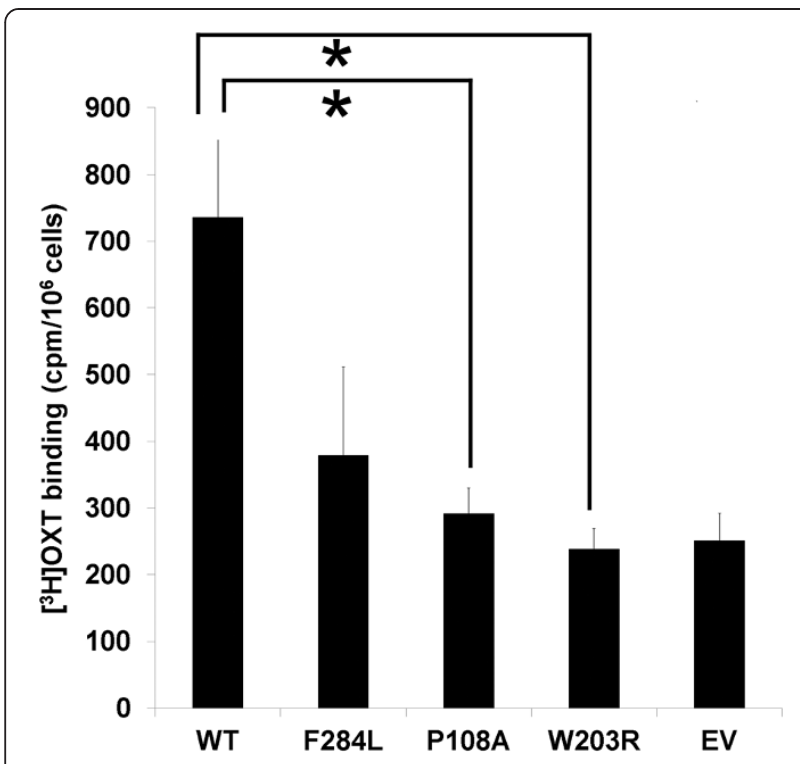

Figure 5 Comparison of specific $\left[{ }^{3} \mathrm{H}\right] \mathrm{OXT}$ binding to wild-type and mutant oxytocin receptors. COS-7 cells were transiently transfected with empty pCDNA3.1 vector and vectors encoding wild-type and mutant OXTRs, and were exposed to $50 \mathrm{nM}\left[{ }^{3} \mathrm{H}\right] \mathrm{OXT}$ in the absence and presence of $20 \mu \mathrm{M}$ unlabeled oxytocin. Specific binding was determined as described in Methods. Statistical significance of differences in $\left[^{3} \mathrm{H}\right] \mathrm{OXT}$ specific binding between wildtype- and mutant-transfected cells was determined using one-way ANOVA followed by Dunnett's test. Data presented are mean in $\mathrm{cpm} / 10^{6}$ cells \pm SEM of multiple experiments performed in duplicate. ${ }^{*} p<0.05$

\section{Discussion}

Pregnancy and parturition involve an intricate biochemical and molecular interplay between mother and fetus [10]. The study of PTB has been hampered by incomplete knowledge of these complex, time-varying processes, and an investigation of static makers like sequence variants may serve as one way to predict the risk of PTB.
In this study, we used a candidate gene approach to better understand genetic factors contributing to PTB. Previous studies have identified some polymorphisms suggestively associated with PTB, but with a focus mostly on immune-related and inflammatory genes such as interleukin 1 receptor antagonist (IL1RN), interferon gamma (IFNG), and coagulation factor II (F2) [15]. The present study was undertaken to explore the contribution of genetic variations in another functionally relevant pathway, the oxytocin pathway to the etiology of PTB, given the important role of constituents of the pathway in labor and parturition.

Our analysis of fourteen SNPs in OXT, OXTR, and $L N P E P$ revealed no evidence of fetal genetic effects on PTB. However, the analysis of maternal genetic effects performed all GA cases identified three SNPs in LNPEP that correlate with prematurity when not corrected for multiple comparisons. This finding is in line with the results of recent studies demonstrating that the maternal genome has a major impact on the risk of prematurity $[35,36]$ and can be considered hypothesis generating for further investigations in the role of $L N P E P$ in preterm labor (PTL).

Ishii et al. [37] reported that in LNPEP knockout mice, an increased sensitivity to OXT is observed and pregnancy duration is significantly shortened, providing functional evidence supporting our genetic data. It was noted that the same three LNPEP SNPs showing suggestive association in the analysis of all GAs remained significant in the GA-stratified analysis, further supporting the importance of these SNPs. The activity of LNPEP is known to gradually increase during late pregnancy and reach a very high level at 11 days before the onset of labor [37]. Interestingly, in our five-week sliding window analysis for maternal effects, the three SNPs were found to be significant in late GA groups (30-34, 31-35, and 32-36 week
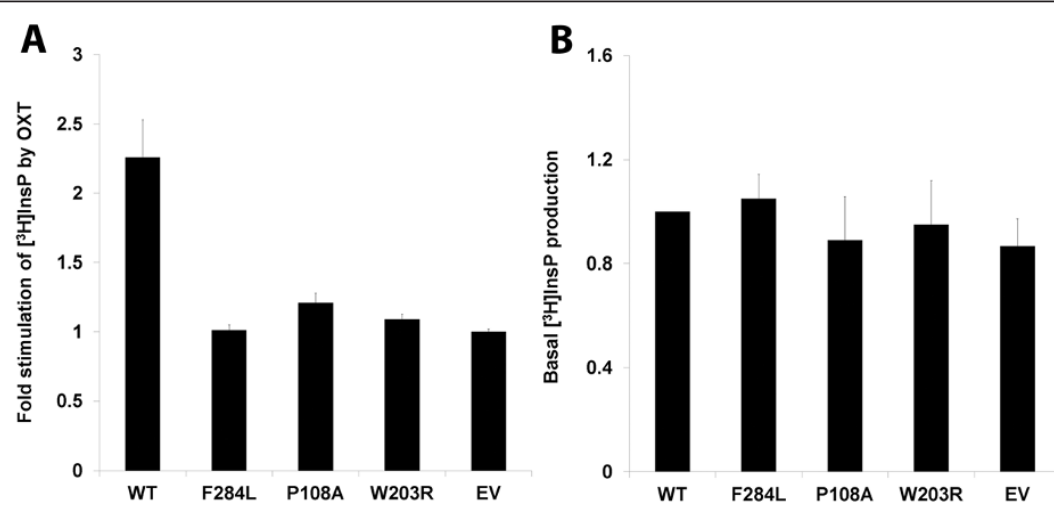

Figure 6 Inositol phosphate (InsP) accumulation in COS-7 cells transiently transfected with wild-type and mutant OXTRs. Transfected cells prelabeled with myo-[ $\left.{ }^{3} \mathrm{H}\right]$ inositol were treated with buffer alone or with $100 \mathrm{nM}$ oxytocin. After one hour of incubation, inositol phosphate accumulation was measured as described in Methods. (A) Oxytocin-stimulated InsP accumulation. Results are presented as fold change compared with unstimulated (basal) InsP levels. (B) Comparison of basal levels of InsP accumulation in transfected cells. Results are presented as the ratio to the unstimulated (basal) InsP levels in cells expressing wild-type receptor. Data are mean \pm SEM of multiple experiments performed in duplicate. 
groups) although there was an additional significant SNP (rs13175726) detected for the 26-30 week group. Pending replication with larger samples, we postulate that these polymorphisms, all of which are non-coding SNPs, may serve as regulatory elements for the LNPEP gene rather than having a direct functional effect.

We screened the OXTR gene for rare genetic variation by resequencing and identified both previously reported and unreported rare variants in exon 3, which is highly conserved across species (Additional file 3). The variants identified were not found to be significantly associated with PTB, but these results should be interpreted cautiously because of the small sample size and the paucity of sequencing data on controls, especially those from Argentina and the U.S.

Our analysis comparing the rare variants identified by sequencing with those catalogued in the public databases demonstrates that some of the rare variants may be of etiologic importance. The observation that three (P108A, W203R, and F284L) of the four rare missense variants not found in either the 1000GP [28,29] or the NHLBI_ESP [30] data were predicted to affect the function of the receptor protein particularly merits further attention. These results suggest that rare OXTR coding variants appear to make some contribution to the genetic risk of prematurity, but larger studies will be needed to measure their combined as well as individual impact more accurately and determine the diagnostic or therapeutic relevance of the findings.

We studied the role of maternal OXTR genotype in PTB in more depth using maternal grandparent-mother triads. Transmission disequilibrium analysis revealed no significant transmission distortion of the OXTR coding variants examined when the analysis was performed on all GA cases or stratified into 3 GA groups. However, two missense SNPs (rs4686302 and rs237902) showed nominal associations in the U.S. triads for the sliding window GA subgroups primarily involving 24-32 weeks of gestation. These results suggest GA-specific effects of maternal genotypes of these OXTR SNPs on susceptibility to PTB.

We characterized the effects of three mutations of potential functional significance with in vitro assays. Our radioligand binding assay revealed that $\mathrm{P} 108 \mathrm{~A}$ and W203R mutant-transfected cells display significantly diminished levels of $\left[{ }^{3} \mathrm{H}\right] \mathrm{OXT}$ specific binding, compared to wild-type-transfected cells. Although it should be further clarified if the mutations affect OXTR protein expression, ligand binding affinity, or both, our results indicate the importance of these residues in receptor function and support previous findings that the first and second extracellular loops of OXTR, where P108 and W203 residues, respectively, are located, are important for agonist binding and selectivity [38]. Despite their important biological effects, it is yet unclear how the mutations may contribute to the disease as it is counterintuitive that attenuated OXT signaling leads to PTB. However, it is possible that the variants may act indirectly to stimulate uterine contractions. Given that the regulation of OXTR function is dependent on steroids such as estradiol, progesterone, and its metabolites [39-41], it is probable that the mutations may affect receptor-hormone interaction in a way that interferes with the timely onset of labor.

Another mutation, F284L, also exhibited a reduced level of specific binding, but the result did not quite reach statistical significance. An earlier mutagenesis study has shown that when two transmembrane residues Y209 and F284 are mutated to F and Y residues, respectively, arginine vasopressin (AVP), a partial agonist of the OXTR, becomes a full agonist $[8,42]$. The finding indicates that these residues may be critical for modulation of the receptor response to AVP. Given the uterotonic action of AVP [43], an investigation into the sensitivity of the F284 as well as the other two mutants to other agonists like AVP could possibly provide an explanation about the pathogenic effects of those mutations.

Our study has certain limitations. First of all, the sample size of our association study may not be large enough to provide sufficient statistical power for the analysis of rare variants with small effects. Second, the functional assays were not carried out in a cellular context relevant to address mechanisms of PTB. The functional role of the identified OXTR mutations should be determined using physiologically more relevant cell types such as uterine myometrial cells. In addition, we only focused on the InsP pathway to examine the downstream effects of the OXTR mutations. We did not observe any significant difference in OXT-induced InsP production between wild type and mutant receptorexpressing cells, and it is possible that their effects are mediated through other signal transduction pathway(s). Therefore, it would be important to examine the impact of the mutations on different biologic pathways like the MAP kinase pathway [44].

\section{Conclusions}

This study provides preliminary evidence for an association between maternal common polymorphisms in the $\angle N P E P$ gene and the risk of PTB. In addition, we found that maternal OXTR missense SNPs rs4686302 and rs237902 may have gestational age-dependent effects on prematurity. These observations support that sequence variants in maternal genes may have a primary role in susceptibility to PTB. Most of the OXTR rare variants identified do not appear to significantly contribute to the risk of PTB. However, the importance of the nonsynonymous rare variants shown to cause altered ligand 
binding warrants further investigation. Future genetic studies with larger sample sizes are needed to confirm the findings of the association analyses performed in the present study. Additional functional studies may provide more detailed insight into the precise physiological effects and clinical significance of the genetic variants identified and ultimately, accelerate translation of such findings into genetic-based diagnostic and therapeutic applications.

\section{Additional files}

Additional file 1: Table S1. List of rare missense variants in exon 3 of OXTR catalogued in public databases (1000GP, NHLBI_ESP).

Additional file 2: Table S2. Results of regression analyses of OXTR coding variants predicting gestational age (GA) in Danish case and control mothers.

Additional file 3: Table S3. Alignment of the amino acid sequence of OXTR from different species at mutant residues of all coding variants identified in the present study.

\section{Abbreviations}

AVP: Arginine vasopressin; BW: Birth weight; CHR: Chromosome; dbSNP: Single nucleotide polymorphism database; DNBC: Danish National Birth Cohort; ECL: Extracellular loop; END: Extracellular N-terminal domain; FBAT: Family Based Association Test; F2: Coagulation factor II (thrombin); GA: Gestational age; HEPES: 4-(-2- hydroxyethyl)-1-piperazineethanesulfonic acid; HWE: Hardy-Weinberg equilibrium; ICL: Intracellular loop; IFNG: Interferon, gamma; InsP: Inositol phosphate; IL1RN: Interleukin 1 receptor antagonist; IRB: Institutional Review Board; LNPEP: Leucyl/cystinyl aminopeptidase; MAF: Minor allele frequency; MAP: Mitogen-activated protein; MT: Maternal triad; N/A: Not available; NHLBI_ESP: The National Heart, Lung, and Blood Institute Grand Opportunity Exome Sequencing Project; OR: Odds ratio; OXT: Oxytocin; OXTR: Oxytocin receptor; PLAP: Placental alkaline phosphatase; P1: Phase 1; P2: Phase 2; PTB: Preterm birth; PTD: Preterm delivery; PTL: Preterm labor; SIFT: Sorting intolerant from tolerant; SNP: Single nucleotide polymorphism; TDT: Transmission disequilibrium test; 1000GP: The 1000 Genomes Project; TMD: Transmembrane domain

\section{Competing interests}

The authors declare that they have no competing interests.

\section{Authors' contributions}

JK performed SNP genotyping, sequencing, comparative sequence analysis, and functional assays (including data analysis), and drafted and revised the manuscript and prepared figures and tables. KJS carried out SNP genotyping and sequencing, in part, and drafted part of the manuscript. MEC conducted statistical analyses of SNP genotype (fetal genetic effects) and sequencing (Danish cohort, maternal triads, and lowa cases and controls) data, and assisted in study design. MA was involved in the analysis of functional assay data and assisted in study design. AMM participated in the management and preparation of genotyping and sequencing samples and data for analysis. KKR participated in statistical analysis of Danish sequencing data. ELM performed maternal triad sequencing. LR was involved in the management and sequencing of Danish cohort samples. KLS helped with sample organization. VC, EG, and CS coordinated patient recruitment, phenotyping, and sample collection, and assisted in study design. MS conducted statistical analysis of SNP genotype (maternal genetic effects) data. MH, JP, KAT, and LM provided Finnish DNA samples. BF, FG, HAB, and MM provided Danish DNA samples and patient information, and were involved in study design and discussion of statistical analysis of Danish sequencing data. MLM participated in study design and discussion of statistical analysis of genotype and sequencing data. JMD assisted in study design and reviewed the draft of the manuscript. JCM is the principal investigator and obtained funding, established key collaborations, provided study design and supervision, and oversaw manuscript preparation. All authors read and approved the final manuscript.

\section{Acknowledgements}

We thank, in particular, the families that participated in this study and we are ever grateful for the clinical care provided by our colleagues that allowed those families to be enrolled. The research nurses Susan Berends, Gretchen Cress, Karen Johnson, Laura Knosp, Nancy Krutzfield, Silvina Argañaraz, Mirta Gladys Leguizamón, Mercedes López, Marta Padilla, and Azucena Singh were essential in contacting, enrolling and sampling families. Kristin Orr, Cara Zimmerman, Keegan Kelsey, Marla K. Johnson, and Tamara Busch were integral in sample organization or testing. We acknowledge Elizabeth Leslie for her help in obtaining the 1000GP data as well as her input on the analysis of the reference sequence data. Susie McConnell, Dan Benton, Erin Brothers-Smith, and Nancy Davin were essential in administration. The authors would like to thank the NHLBI GO Exome Sequencing Project and its ongoing studies which produced and provided exome variant calls for comparison: the Lung GO Sequencing Project (HL-102923), the WHI Sequencing Project (HL-102924), the Broad GO Sequencing Project (HL102925), the Seattle GO Sequencing Project (HL-102926) and the Heart GO Sequencing Project (HL-103010). This work was supported by the National Institutes of Health [R01 HD052953 and HD57192 to J.C.M., Z01 ES040007 and Z01 ES045002 to M.S.]; and the March of Dimes Foundation [FY2006-575 and FY2008-260 to J.C.M., 21-FY07-597 to L.J.M.].

\section{Author details}

${ }^{1}$ Department of Anatomy and Cell Biology, University of lowa, lowa City, IA 52242, USA. ${ }^{2}$ Department of Pediatrics, University of lowa, lowa City, IA 52242, USA. ${ }^{3}$ Center for Craniofacial and Dental Genetics, Department of Oral Biology, School of Dental Medicine, University of Pittsburgh, Pittsburgh, PA 15219, USA. ${ }^{4}$ Department of Pharmacology, University of lowa, lowa City, IA 52242, USA. ${ }^{5}$ Centro de Educación Médica e Inverstigaciones Clínicas, Buenos Aires 1431, Argentina. ${ }^{6}$ Instituto de Maternidad y Ginecología Nuestra Señora de las Mercedes, San Miguel de Tucumán 4000, Argentina. ${ }^{7}$ Biostatistics Branch, National Institute of Environmental Health Sciences, Research Triangle Park, NC 27709, USA. ${ }^{8}$ Institute of Clinical Medicine, Department of Pediatrics, University of Oulu, Oulu 90014, Finland. ${ }^{9}$ Human and Statistical Genetics Program, Washington University, St. Louis, MO 63110, USA.

${ }^{10}$ Department of Obstetrics and Gynecology, University of Helsinki, Helsinki 00290, Finland. ${ }^{11}$ Perinatal Institute, Cincinnati Children's Hospital Medical Center and Department of Pediatrics, University of Cincinnati College of Medicine, Cincinnati, OH 45229, USA. ${ }^{12}$ Department of Epidemiology Research, Statens Serum Institut, Copenhagen, S 2300, Denmark.

${ }^{13}$ Department of Human Genetics, Graduate School of Public Health, University of Pittsburgh, Pittsburgh, PA 15219, USA.

Received: 12 March 2012 Accepted: 18 July 2013 Published: 26 July 2013

\section{References}

1. Dizon-Townson DS: Preterm labour and delivery: a genetic predisposition. Paediatr Perinat Epidemiol 2001, 15:57-62.

2. Beck S, Wojdyla D, Say L, Pilar Betran A, Merialdi M, Harris Requejo J, Rubens C, Menon R, Van Look P: The worldwide incidence of preterm birth: a systematic review of maternal mortality and morbidity. Bull World Health Organ 2010, 88:31-38.

3. Martin JA, Hamilton BE, Ventura SJ, Osterman MJ, Mathews TJ: Births: final Data for 2011. Natl Vital Stat Rep 2013, 62(1):1-90.

4. Gotsch F, Romero R, Erez O, Vaisbuch E, Kusanovic JP, Mazaki-Tovi S, Kim SK, Hassan S, Yeo L: The preterm parturition syndrome and its implications for understanding the biology, risk assessment, diagnosis, treatment and prevention of preterm birth. J Matern Fetal Neonatal Med 2009, 22(Suppl 2):5-23.

5. Crider KS, Whitehead N, Buus RM: Genetic variation associated with preterm birth: a huge review. Genet Med 2005, 7(9):593-604.

6. Adams KM, Eschenbach DA: The genetic contribution towards preterm delivery. Semin Fetal Neonatal Med 2004, 9(6):445-452.

7. Muglia $L$, Katz M: The enigma of spontaneous preterm birth. N Eng J Med 2010, 362(6):529-535.

8. Gimpl G, Fahrenholz F: The oxytocin receptor system: structure, function, and regulation. Physiol Rev 2001, 81(2):629-683. 
9. Blanks AM, Shmygol A, Thornton S: Regulation of oxytocin receptors and oxytocin receptor signaling. Semin Reprod Med 2007, 25(1):52-59.

10. Trzidou V: Biochemical and endocrinological preparation for parturition. Best Pract Res Clin Obstet Gynaecol 2007, 21:729-756.

11. Vrachnis N, Malamas FM, Sifakis S, Deligeoroglou E, lliodromiti Z: The oxytocin-oxytocin receptor system and its antagonists as tocolytic agents. International journal of endocrinology 2011, 2011:350546.

12. Lampelo $S$, Vanhaperttula T: Fractionation and characterization of cystine aminopeptidase (oxytocinase) and arylamidase of human serum during pregnancy. J Reprod Fertil 1980, 58(1):225-235.

13. Nomura S, Ito T, Yamamoto E, Sumigama S, Iwase A, Okada M, Shibata K, Ando H, Ino K, Kikkawa F, et al: Gene regulation and physiological function of placental leucine arninopeptidase/oxytocinase during pregnancy. Biochimica Et Biophysica Acta-Proteins and Proteomics 2005, 1751(1):19-25

14. Tsatsaris V, Carbonne B, Cabrol D: Atosiban for preterm labour. Drugs 2004, 64(4):375-382

15. Dolan SM, Hollegaard MV, Merialdi M, Betran AP, Allen T, Abelow C, Nace J, Lin BK, Khoury MJ, loannidis JP, et al: Synopsis of preterm birth genetic association studies: the preterm birth genetics knowledge base (PTBGene). Public Health Genomics 2010, 13(7-8):514-523.

16. Olsen J, Melbye M, Olsen SF, Sorensen TI, Aaby P, Andersen AM, Taxbol D, Hansen KD, Juhl M, Schow TB, et al: The Danish national birth cohort-its background, structure and aim. Scand J Public Health 2001, 29(4):300-307.

17. Ehn NL, Cooper ME, Orr K, Shi M, Johnson MK, Caprau D, Dagle J, Steffen K, Johnson K, Marazita ML, et al: Evaluation of fetal and maternal genetic variation in the progesterone receptor gene for contributions to preterm birth. Pediatr Res 2007, 62(5):630-635.

18. Ascoli M, Pignataro OP, Segaloff DL: The inositol phosphate/diacylglycerol pathway in MA-10 leydig tumor cells. Activation by arginine vasopressin and lack of effect of epidermal growth factor and human choriogonadotropin. J Biol Chem 1989, 264(12):6674-6681.

19. Purcell S, Neale B, Todd-Brown K, Thomas L, Ferreira M, Bender D, Maller J, Sklar P, de Bakker P, Daly M, et al: PLINK: a tool set for whole-genome association and population-based linkage analyses. Am J Hum Genet 2007, 81(3):559-575.

20. Barrett JC, Fry B, Maller J, Daly MJ: Haploview: analysis and visualization of LD and haplotype maps. Bioinformatics 2005, 21(2):263-265.

21. Rabinowitz D, Laird N: A unified approach to adjusting association tests for population admixture with arbitrary pedigree structure and arbitrary missing marker information. Hum Hered 2000, 50(4):211-223.

22. Laird NM, Horvath $S, X u X:$ Implementing a unified approach to familybased tests of association. Genet Epidemiol 2000, 19:S36-S42

23. Spielman RS, McGinnis RE, Ewens WJ: Transmission test for linkage disequilibrium: the insulin gene region and insulin-dependent diabetes mellitus (IDDM). Am J Hum Genet 1993, 52(3):506-516.

24. Weinberg CR, Wilcox AJ: Distinguishing the effects of maternal and offspring genes through studies of 'case-parent triads' " and "a new method for estimating the risk ratio in studies using case-parental control design. Am J Epidemiol 1999, 150(4):428-429.

25. Schaid DJ, Sommer SS: Genotype relative risks: methods for design and analysis of candidate-gene association studies. Am J Hum Genet 1993, 53(5):1114-1126.

26. Weinberg CR: Allowing for missing parents in genetic studies of caseparent triads. Am J Hum Genet 1999, 64(4):1186-1193.

27. Shi M, Umbach DM, Vermeulen SH, Weinberg CR: Making the most of case-mother/control-mother studies. Am J Epidemiol 2008, 168(5):541-547.

28. The 1000 Genomes Project Consortium: A map of human genome variation from population-scale sequencing. Nature 2010, 467(7319):1061-1073.

29. The 1000 genomes project. http://www.1000genomes.org/.

30. Exome variant server, NHLBI exome sequencing project (ESP). Seattle, WA. (URL: http://evs.gs.washington.edu/EVS/) [date (February, 2013) accessed]

31. The SeattleSeq annotation server. [http://gvs.gs.washington.edu/ SeattleSeqAnnotation/]

32. Dolan SM: Genetic and environmental contributions to racial disparities in preterm birth. Mt Sinai J Med 2010, 77(2):160-165.

33. Ramensky V, Bork P, Sunyaev S: Human non-synonymous SNPs: server and survey. Nucleic Acids Research 2002, 30(17):3894-3900.

34. Ng PC, Henikoff S: Accounting for human polymorphisms predicted to affect protein function. Genome Research 2002, 12(3):436-446.
35. Boyd HA, Poulsen G, Wohlfahrt J, Murray JC, Feenstra B, Melbye M: Maternal contributions to preterm delivery. American Journal of Epidemiology 2009, 170(11):1358-1364.

36. Svensson AC, Sandin S, Cnattingius S, Reilly M, Pawitan Y, Hultman CM, Lichtenstein P: Maternal effects for preterm birth: a genetic epidemiologic study of 630,000 families. American Journal of Epidemiology 2009, 170(11):1365-1372

37. Ishii M, Naruse K, Hattori A, Tsujimoto M, Ishiura S, Numaguchi Y, Murohara T, Kobayashi H, Mizutani S: Oxytocin hypersensitivity in pregnant P-LAP deficient mice. Life Sciences 2009, 84(19-20):668-672.

38. Postina R, Kojro E, Fahrenholz F: Separate agonist and peptide antagonist binding sites of the oxytocin receptor defined by their transfer into the V-2 vasopressin receptor. Journal of Biological Chemistry 1996, 271(49):31593-31601.

39. Grazzini E, Guillon G, Mouillac B, Zingg HH: Inhibition of oxytocin receptor function by direct binding of progesterone. Nature 1998, 392(6675):509-512

40. Gellersen B, Fernandes MS, Brosens JJ: Non-genomic progesterone actions in female reproduction. Hum Reprod Update 2009, 15(1):119-138.

41. Dunlap KA, Stormshak F: Nongenomic inhibition of oxytocin binding by progesterone in the ovine uterus. Biol Reprod 2004, 70(1):65-69.

42. Chini B, Mouillac B, Balestre MN, TrumppKallmeyer S, Hoflack J, Hibert M, Andriolo $M$, Pupier $S$, Jard $S$, Barberis C: Two aromatic residues regulate the response of the human oxytocin receptor to the partial agonist arginine vasopressin. Febs Letters 1996, 397(2-3):201-206

43. Chan WY, Wo NC, Manning M: The role of oxytocin receptors and vasopressin $\mathrm{V}$-1a receptors in uterine contractions in rats: implications for tocolytic therapy with oxytocin antagonists. American Journal of Obstetrics and Gynecology 1996, 175(5):1331-1335.

44. Tahara A, Tsukada J, Tomura Y, Wada K, Kusayama T, Ishii N, Yatsu T, Uchida W, Tanaka A: Pharmacologic characterization of the oxytocin receptor in human uterine smooth muscle cells. British Journal of Pharmacology 2000 129(1):131-139.

doi:10.1186/1471-2350-14-77

Cite this article as: Kim et al: Sequence variants in oxytocin pathway genes and preterm birth: a candidate gene association study. BMC Medical Genetics 2013 14:77.

\section{Submit your next manuscript to BioMed Central and take full advantage of:}

- Convenient online submission

- Thorough peer review

- No space constraints or color figure charges

- Immediate publication on acceptance

- Inclusion in PubMed, CAS, Scopus and Google Scholar

- Research which is freely available for redistribution
C Biomed Central 